\title{
U usm Eitlat

\section{O cinema como arte e dispositivo midiático potencializador de atos de currículo multirreferenciais no ensino superior}

Cinema as an art and media device that enhances multireferential curricula in higher education

Mirian Maia do Amaral

Fundação Getúlio Vargas

Rosemary dos Santos

Universidade Estadual do Rio de Janeiro

Edméa Oliveira Santos

Universidade Federal Rural do Rio de Janeiro

Recebido em 04 de junho de 2018

Aprovado em 14 de fevereiro de 2019

\section{RESUMO}

A cibercultura, cenário contemporâneo, mediado por tecnologias digitais em rede, vem impactando, significativamente, processos educativos e alterando dinâmicas sociocomunicacionais e culturais. No contexto da mídia-educação, como produtor de estranhamento de si e do mundo, o cinema estimula o surgimento de reflexões e formas de expressão diversas. Constitui, ainda, um potente dispositivo didáticopedagógico; sobretudo quando utilizado para além da perspectiva instrucional/informacional na composição dos currículos escolares voltados ao ensino superior. Alinhados à abordagem da pesquisa nos cotidianos escolares, na multirreferencialidade e nos princípios da pesquisa-formação na cibercultura, utilizamos o filme "Um Conto Chinês", para criar atos de currículo na perspectiva de uma ecologia de saberes, uma pedagogia das emergências e uma artesania das práticas ${ }^{1}$. Desse modo, possibilitamos aos estudantes o desenvolvimento de novas visões de mundo, que contemplam, entre outras questões, a diversidade cultural e a alteridade, entrelaçando arte e educação, no contexto da pesquisa desenvolvida no Curso de Graduação em Educação da Universidade do Estado do Rio de Janeiro UERJ, realizada no âmbito da disciplina Cotidianos e Currrículos, durante estágio de doutoramento.

Palavras-chave: Cinema; Atos de currículo; Multiculturalidade.

\footnotetext{
${ }^{1}$ Os termos ecologia de saberes (conjunto de saberes científicos e saberes comuns); pedagogia das emergências (que respeita a realidade brasileira de diversidade e pluralismo); e a artesania das práticas (uso de metodologias participativas que acentuam o caráter dialógico, interativo, colaborativo e autoral do processo educativo) são termos apresentados por Boaventura Santos, em Conferência, proferida no. IX Seminário Internacional. As redes educativas e as tecnologias: educação e democracia - aprenderensinar para um mundo plural e igualitário, realizada na UERJ, em 2017.
} 


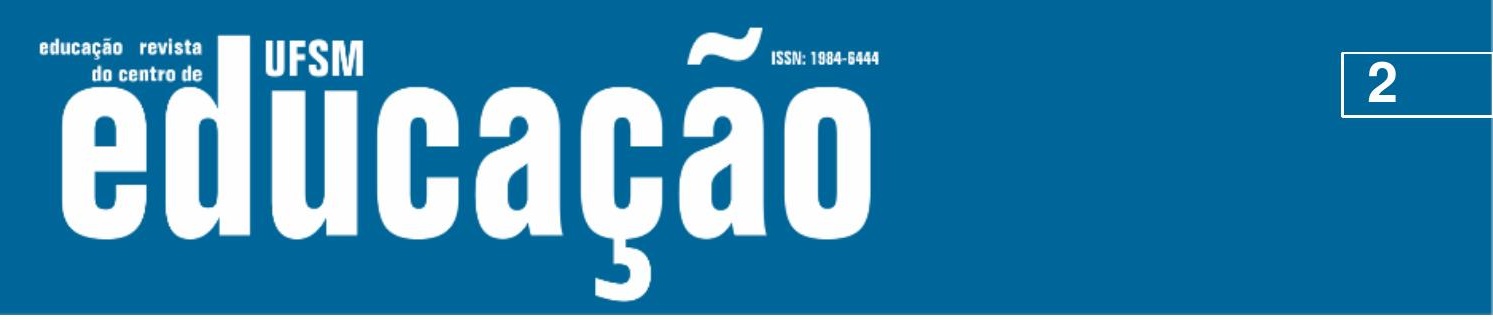

ISSN: 1984-6444 | http://dx.doi.org/10.5902/1984644432935

\section{ABSTRACT}

The cyberculture, a contemporary scenario mediated by digital network technologies, has been significantly impacting educational processes and altering sociocommunication and cultural dynamics. In the context of media-education, the cinema, as a producer of estrangement from itself and the world, stimulates the emergence of reflections and various forms of expression. It is also a powerful didacticpedagogical device, specially when used in addition to the instructional / informational perspective in the composition of school curricula focused on higher education.. In line with the research approach in school everyday, in multireferentiality and the principles of research-training in cyberculture, we used the film "A Chinese Story", to create curriculum acts, from the perspective of an ecology of knowledge, an pedagogy of emergencies and a craft of practices. In this way, we enabled the development of new worldviews, which included, among other issues, cultural diversity and otherness, intertwining art and education, in the context of a research carried out within the scope of the Everyday and Currículo develop Graduate Education Course of the State University of Rio de Janeiro - UERJ, during PhD.

Keywords: Cinema; Cultural diversity; Otherness.

\section{Introdução}

A relação do cinema com a educação brasileira não é recente. Nos anos 20, o cinema era anunciado como entretenimento, e suas produções vistas como potencialmente educativas, devendo ser introduzidas no ambiente escolar, mediante projetos educacionais. Esse entendimento estendeu-se, ao longo do século $X X$, nas práticas pedagógicas e orientações curriculares que nortearam o processo de aprendizagem, e ainda se faz presente em alguns espaçostempos ${ }^{2}$ escolares, como se fora uma marca de origem, que lhe confere um caráter fortemente instrumental (DUARTE; ALEGRIA, 2008); em outras palavras, a exibição de filmes volta-se, exclusivamente, para o ensino de conteúdos curriculares, sem levar em conta sua dimensão estética, seu valor cultural e o lugar que tal obra ocupa na história do cinema.

Como nos ensina Deleuze (2007), na medida em que cada um desses campos se afetam, mutuamente, essa relação deve possibilitar o exercício da alteridade, de

\footnotetext{
${ }^{2}$ Adotamos o uso dos termos espaçostempos, aprendizagemensino, dentrofora, entre outros, escritos de forma diferenciada, inspirados no referencial teórico de Alves (2008) sobre as pesquisas nos cotidianos no qual, a junção de termos e a sua inversão, em alguns casos, quanto ao modo como são normalmente enunciados, objetiva "mostrar os limites para as pesquisas nos/dos/com os cotidianos, do modo dicotomizado criado pela ciência moderna para analisar a sociedade". (ALVES, 2008, p.11).
} 


\section{F HEM eltioarao

ISSN: 1984-6444 | http://dx.doi.org/10.5902/1984644432935

forma a conduzir a educação a novos lugares; a pensar o diferente, ao produzir certo estranhamento à função comunicativa da educação, levando-a a novos devires, marcas dos novos tempos.

Desse modo, não basta utilizar esses dispositivos midiáticos sob a ótica instrumental, como simples fontes de informação ou repositórios de materiais. É preciso avançar, pois como afirma Freire (2004, p. 33) "transformar a experiência educativa em puro treinamento técnico é amesquinhar o que há de fundamentalmente humano no exercício educativo: o seu caráter formador". Se "aprender é uma aventura criadora" (p. 69), como acentua o autor, desenvolver o potencial criador de nossos alunos, para que sejam produtores de seus conhecimentos, demanda apropriar-se desses dispositivos, de forma adequada, e explorar todas as suas potencialidades, tendo como um de seus pilares, a artesania das práticas (SANTOS, B., 2017).

Nessa perspectiva, a emergência das tecnologias digitais em rede, responsável pelas transformações dos processos de comunicação, de sociabilidade, de educação e de aprendizagem, tem-nos convidado a pensar a relação entre educação e arte, particularmente no que se refere às projeções cinematográficas, como dispositivos que favorecem a criação de currículos que visam ao desenvolvimento de processos reflexivos e críticos.

Se, como afirma Fresquet (2013), as artes atravessam as certezas, ainda mais se produzidas nos espaços educativos, provocando-as, constituem-se como um outro $^{3}$ em relação a nós, professores e estudantes, "espelhando-nos com seu olhar, devolvendo nossa própria imagem com outras cores e formas. [ ]. Também se revelam uma janela para descobrir um mundo inacabado, ávido de transformações e de memórias para projetar futuros" (p. 9).

Experiências e processos criativos se aproximam e são potencializados, quando criamos espaços de diálogo entre educação e arte, ultrapassando os limites

3 Quando somos afetados pela experiência cinematográfica, afirmamos a corporeidade e ressignificamos a alteridade, na medida em que estabelecemos relações com o outro; esse outro tão diferente de nós, que pode ser um filme, um personagem, uma língua desconhecida, uma idade, um lugar, etc.. Esse outro como 'diferença' (GALLO, 2008), para além da sua representação, mostra-nos potência em si mesmo. 


\section{Wusm oltibarato

ISSN: 1984-6444 | http://dx.doi.org/10.5902/1984644432935

estabelecidos pelos explicativos, fazendo manifesto a dimensões outras que produzem conhecimento a partir do arrebatamento, do arrepio, da falta de domínio de si, sem estruturação lógica. Nessa perspectiva, a cultura é matéria-prima no processo de significação e no imbricamento de experiências intelectuais e sensíveis.

Para a autora, ao se levar a arte para os espaços educativos, imprime-se enorme responsabilidade na reinvenção de si e do mundo com o outro, a partir de uma relação de alteridade, com vistas à construção de textos que dialoguem com a vida e, de algum modo se façam vida, ao tocar o sujeito. Essa experiência propicia ao sujeito desenvolver novas visões de si e do mundo, ultrapassando os limites do que Ihe é dado.

Sob essa ótica, o cinema pode ser entendido sob as perspectivas estética, cognitiva, social e psicológica; ou seja, não basta abordá-lo apenas do ponto de vista informacional/instrumental, e meio de realização de pesquisa. É preciso explorar todas as suas potencialidades, integrando-o a práticas pedagógicas que acentuam o caráter dialógico, interativo, colaborativo e autoral do processo educativo (AMARAL,2014).

O "paradigma ecológico" da mídia-educação propõe uma concepção integrada de fazer educação usando todos os meios e tecnologias disponíveis (...). Nessa perspectiva ecológica, o objetivo do trabalho educativo (...) não é apenas o uso das tecnologias em laboratórios multimídia, e sim que a criança atue nesse e noutros espaços, estabelecendo interações e construindo relações e significações (FANTIN, 2007, p. 2).

Mais do que arte e entretenimento, as produções cinematográficas, constituemse também como um conjunto de elementos bastante diversificados, tais como 0 mercado, a indústria cultural, o roteiro, o argumento, a produção, os atores, as interpretações e seus resultados. Com seu aparato tecnológico que permite documentar, registrar, de forma ética e estética, e narrar histórias, despontam como um dispositivo que potencializa processos reflexivos, críticos e criativos, favorecendo o desenvolvimento de autorias diversas, a partir de problematizações que vão para além de sua apropriação didática como simples ilustração dos conteúdos formalizados nos programas curriculares oficiais.

Com o digital em rede, produções cinematográficas são cada vez mais utilizadas nas escolas, que ganham vida; ou seja, transformam-se em participantes 


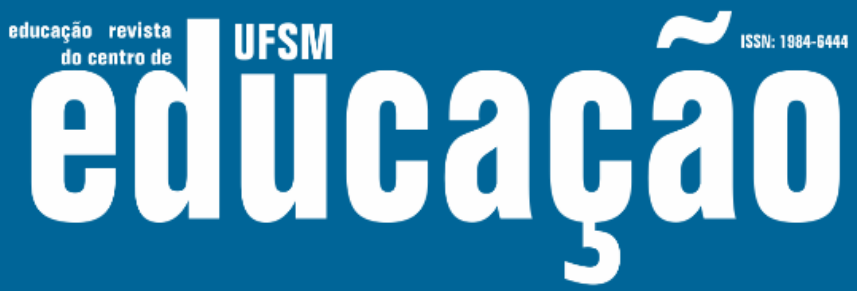

ISSN: 1984-6444 | http://dx.doi.org/10.5902/1984644432935

ativas e criativas dos movimentos da cultura, e não, simplesmente, repetidoras e divulgadoras de conhecimentos massificados, geralmente defasados e inadequados para o cenário contemporâneo.

Seja na sociedade em geral, ou em espaços educativos, em particular, o cinema, ao ditar valores, linguagens, costumes e tantos outros elementos, influencia o espectador muito mais pela forma como os assuntos são tratados, do que pela natureza desses temas, propriamente ditos. Daí, a importância de se considerar, em suas análises, os diferentes aspectos da linguagem utilizada: os ângulos e enquadramentos da câmera, a montagem dos planos e sequências, a fotografia, quanto a sua textura e cores da imagem, além do fio condutor da trama - sua narrativa.

Visto como imagem em movimento, o cinema pode contribuir para melhor compreensão de como a cultura escolar é representada nas peças cinematográficas; além de se constituir num desencadeador de reflexões compartilhadas, assevera Souza (2014). Como recursos didáticos, o uso de filmes pode ensejar o conhecimento do outro e de sua cultura, deixando evidente outras realidades e culturas; o que torna a aprendizagem mais significativa e prazerosa.

Para Benjamim (1996) e Didi-Huberman (2011), as imagens aparecem como elementos construtivos e depositários das formas cognitivas; um fio condutor que estabelece o vínculo entre o real e o imaginário, convocando nossos sentidos e a nossa imaginação. Não são apenas recortes do real. Constituem um rastro, um traço do tempo que se quis tocar, associado a outros tempos, possivelmente anacrônicos e heterogêneos que, como memórias, não podem aglutinar. Para aqueles que as captam, ardem em significados e intencionalidades. Mas, ao tocarem o real, convertem-se em cinzas, a serem reacesas por meio das memórias e narrativas dos sujeitos que as tocam.

Nesse contexto, não há como dissociar o olhar, de quem olha; separar o que se vê daquilo em que se acredita; fugir de nossa subjetividade. O que se pode fazer é olhar entre, olhar de forma reflexiva, na busca de ações efetivas para o enfrentamento das questões que se nos colocam. Na aproximação dos saberes, científicos e saberes 


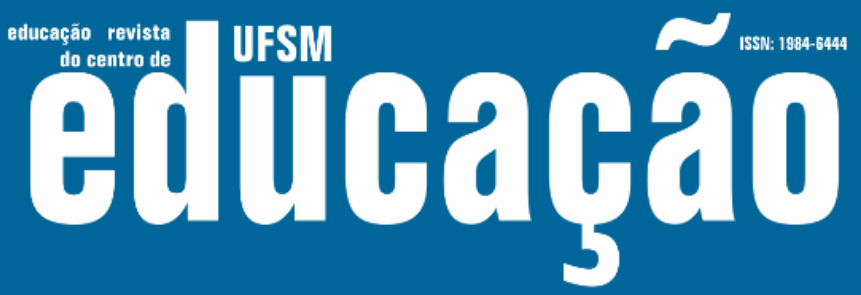

ISSN: 1984-6444 | http://dx.doi.org/10.5902/1984644432935

comuns, é possível realizar uma ação política por meio dessa arte que, por si só, já é educativa.

No entanto, além de sensibilizar o estudante e/ou ensejar atitudes imparciais diante de outros valores, outras tradições, outros modos de ver, viver e nomear a realidade, é imprescindível acolher o outro e compartilhar com ele hábitos, costumes e ideias (COSTA, 2005). Isso implica um olhar plural, direcionado aos fatos, às práticas e aos eventos educativos, a partir de sistemas de referências distintos, enfatiza Macedo (2012).

De forma similar, Xavier e Canen (2008) afirmam que as instituições de ensino devem ser repensadas como o lócus cultural que desvela e combate processos excludentes, promove reflexões sobre a relação entre cultura e poder, desenvolve ideias em torno de uma cidadania crítica, e o respeito à diversidade, às diferenças e à multiplicidade.

Com efeito, do ponto de vista metodológico, é fundamental reconhecer a existência de práticas que não se enquadram no modelo social instituído nos cotidianos escolares (porque invisibilizadas pela modernidade, em suas diversas manifestações), e do seu potencial de multiplicação, a fim de torná-las visíveis.

Epistemologicamente, como enfatiza Santos, B. (2004), é preciso compreender questões relacionadas aos conteúdos escolares, à ideia de progresso social atrelada ao progresso econômico, que visa à preparação do sujeito para o mercado de trabalho, além de nos conscientizarmos de que ao lado do pensamento dominante (eurocêntrico), do saber formal, do tempo linear, da escala global e da tentativa de inviabilização, emergem outras existências diversificadas, desiguais e diferentes, marginalmente esquecidas e soterradas na vida escolar, particularmente no nível superior.

Desse modo, é relevante, no processo formativo dos professores, a incorporação de uma visão multicultural que possa ser traduzida em suas práticas pedagógicas, nos currículos praticados, entendidos como processos discursivos, permeados por relações de poder desiguais que participam da formação das identidades; o que: 


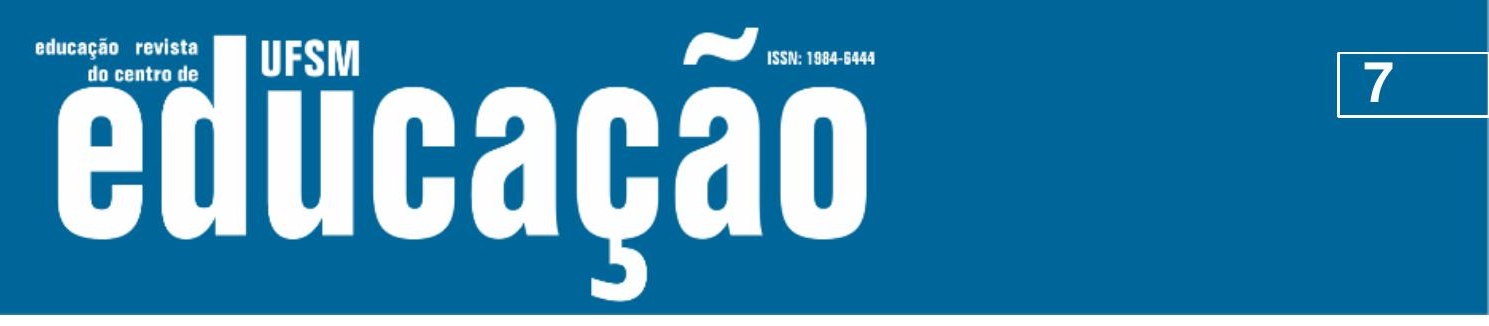

ISSN: 1984-6444 | http://dx.doi.org/10.5902/1984644432935

implica tencionar conteúdos pré-estabelecidos e pretensões a verdades únicas, procurando detectar vozes silenciadas e representadas nesses discursos curriculares, de forma a mobilizar a construção de identidades docentes sensíveis a diversidade cultural e aptas a formular alternativas discursivas transformadoras, desafiadoras do congelamento de identidades $\mathrm{e}$ estereótipos (CANEN; XAVIER, 2005, p. 336).

A partir dessas premissas, objetivamos, neste artigo, à luz do filme "Um Conto Chinês", pensar o cinema como arte e dispositivo midiático potencializador de atos de currículo ${ }^{4}$, que levam em conta a ecologia dos saberes, a pluralidade da realidade brasileira e a artesania das práticas, mediante processos de aprendizagem dialógicos, colaborativos e interativos.

Nessa perspectiva, e fundamentados nos princípios da pesquisa-formação, que tem como característica a intencionalidade formativa, foi possível, à luz da película argentina Um Conto Chinês, discutir, neste artigo, o trinômio cultura, dialogismo e alteridade, em sua inter-relação com a experiência de pesquisa vivenciada durante o processo de doutoramento, na Universidade do Estado do Rio de Janeiro - UERJ.

Apresentamos, a seguir, a sinopse do referido filme.

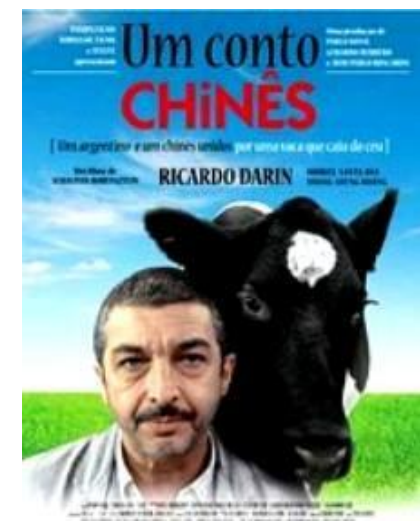

\section{Um Conto Chinês - uma vaca, um argentino, um chinês e 0 acaso}

Dirigido por Sebastián Borensztein, "Um conto chinês" (2011) aborda a história do veterano da Guerra das Malvinas, Roberto, um argentino mal humorado, dono de uma casa de ferragens que, recluso em sua loja, evita qualquer contato humano. No entanto, algo surreal, singular e agudo, no lugar e no momento de sua produção, corta a cena: num lago na China, o chinês Jun, e sua noiva vão trocar as alianças de noivado e são surpreendidos com uma vaca que cai do céu! A balsa em que estavam tomba e a moça morre. O rapaz, então, resolve vir para a Argentina à procura de um tio. Por ironia do destino, Roberto, num final de semana, abandona sua vida rotineira e vai ao cemitério depositar flores no túmulo de seus pais e ouvir música em seu carro, próximo de uma avenida, quando vê um chinês sendo jogado de um táxi. Corre para socorrer o rapaz e, por compaixão, leva-o para casa. Impossibilitados de comunicação, já que Roberto não fala

\footnotetext{
${ }^{4}$ Consiste na expressão dos currículos que criamos em nossas atividades cotidianas, e que mistura elementos das propostas formais e organizadas pelas instituições de ensino com as possibilidades que temos de implantá-las (MACEDO, 2010).
} 


\section{ตปthaคล์}

ISSN: 1984-6444 | http://dx.doi.org/10.5902/1984644432935

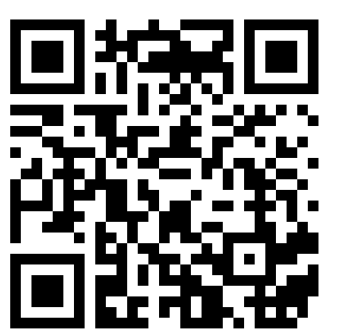

chinês e o rapaz não sabe uma palavra de castelhano, a trama gira em torno de solucionar essa inusitada situação.

Fonte: http://telecine.globo.com/filmes/um-conto-chines/

\section{O mundo está posto. Vivemos uma aldeia multicultural}

$\mathrm{Na}$ contemporaneidade, para além do lugar, das cidades e do país, reina o ciberespaço, pleno de técnicas, conhecimentos, práticas, pensamentos, atitudes, crenças e valores, que desterritorializam, ocupam o imaginário coletivo e fazem emergir novos estilos, visões e sentimentos, que afetam o cotidiano de cada indivíduo. Em tempos de mobilidade ubíqua, cada vez mais grupos de culturas diferentes se aproximam e, como preconizou McLuhan (1964), modelam uma aldeia global - e por que não dizer, uma aldeia multicultural?

Com efeito, a ideia de que todos os indivíduos são iguais, perante a lei, amplamente disseminada pela indústria cultural, atravessa a questão multicultural, ficando as diferenças por conta dos costumes, hábitos e valores, que coabitam com outros valores, muitas vezes, de modo conflituoso. Assim, reconhecer e respeitar a diversidade constitui o primeiro passo para uma convivência harmônica, não apenas na perspectiva legal, mas também sob o ponto de vista humano e social.

Bakhtin (2011) compreende o sujeito como um conjunto de relações sóciohistóricas. Nessa perspectiva, a língua é entendida como um fenômeno social. Por serem variáveis e flexíveis, seu signos lhe conferem um caráter mutável, histórico e polissêmico, não podendo, na prática, ser compreendida e explicada fora desse 


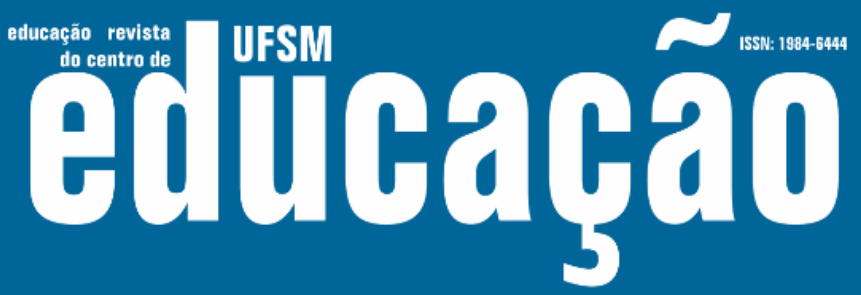

ISSN: 1984-6444 | http://dx.doi.org/10.5902/1984644432935

vínculo. Para o autor, em decorrência das interações verbais dos interlocutores, a língua está em constante evolução. É por meio do enunciado, no contato com a realidade concreta, que a palavra ganha sentido, podendo expressar um juízo de valor, uma significação, que se revela em sua profundidade quando encontra e toca outro sentido, estabelecendo-se entre eles uma relação dialógica que supera o caráter fechado e unívoco da obra.

Em "Um Conto Chinês", o acaso, se ele existe, aproxima os dois personagens - Jun e Roberto, quando este último, sentado numa cadeira, próxima a sua velha Fiat, vê um chinês ser lançado para fora de um táxi, chorando copiosamente. Como desconhece o idioma espanhol, Jun comunica-se por meio de gestos. Dá-se, portanto, um encontro entre estranhos, sem qualquer ligação anterior, nem troca de informações sobre lembranças compartilhadas. Com muito esforço, Jun consegue se fazer entender por Roberto, que o ampara, ainda que o veja como um 'estrangeiro', e que se sinta ameaçado por uma cultura diferente da sua, algo que 'vem de fora'.

Para Sennett (apud BAUMAN, 2001, p. 111), uma cidade é "um assentamento humano em que estranhos têm oportunidade de se encontrar em sua condição de estranhos, saindo do encontro casual, que termina de maneira tão abrupta como começou". Sob esta ótica, o encontro entre os dois personagens constitui um evento sem passado e, se depender de Roberto, sem futuro: "uma história para não ser continuada, uma oportunidade única a ser consumada enquanto dure e no ato, sem adiamento e sem deixar questões inacabadas para outra ocasião" (Idem, p. 111).

Roberto não busca interagir com o chinês; ao contrário, procura homogeneizar a sua identidade, não valoriza sua cultura, não se interessa por conhecer sua língua, seus hábitos e costumes, recriminando tudo que lhe parece diferente, na tentativa de eliminar a ansiedade que isso acarreta sentindo-se à vontade na presença do estranho. Se o convívio com seus iguais já é difícil, conviver com a diferença manifestada em Jun é praticamente impossível ao argentino. Isso fica evidenciado na cena em que Roberto, já em casa, tranca a porta do quarto em que Jun iria ocupar até a manhã do outro dia, manifestação do temor sentido em relação ao outro. Por diversas vezes, tenta se desvencilhar de Jun, pois não se sente responsável por ele, 


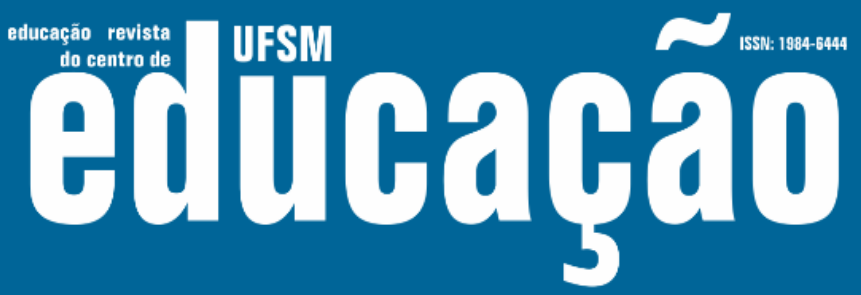

ISSN: 1984-6444 | http://dx.doi.org/10.5902/1984644432935

mas sua consciência fala mais alto, e ele acaba por se enredar mais e mais nessa situação. Como ressalta Bauman (idem), se a proximidade física não pode ser evitada, ela pode, pelo menos, afastar a ameaça de 'estar junto', dispensando o diálogo e a interação. Nesse contexto, a relação entre eles é forçada e tensa e, a linguagem não verbal passa a ser estratégica para que algum tipo de interação social se estabeleça.

Na concepção de Bakhtin (2011), a essência da natureza humana é definida pela alteridade, na medida em que a presença do outro é fundamental para a sua concepção. Assim, torna-se necessário o entendimento de que somos produto dessa interação que, em última instância, constitui parte ativa na construção de nossa identidade. Em outras palavras, "os sujeitos se constituem por meio do(s) outro(s), dialogicamente, numa interatividade complexa e dinâmica, com suas próprias orientações ideológicas" (PAULA, 2008, p. 60).

Desse modo, é natural que, diante de uma nova língua, de uma nova cultura haja, num primeiro momento, certo estranhamento. Dado que o conhecimento de nossa cultura pressupõe o conhecimento de outras culturas, é preciso compreender e conviver com o que é diferente, com aquilo que não nos é familiar, reconhecendo que somos uma cultura entre tantas outras; mas não a única. No entanto, como vimos no filme, ainda que Jun tente se comunicar com Roberto, utilizando recursos extraverbais, a interlocução não acontece, devido ao escapismo deste último, e sua incapacidade de se refletir no outro (alteridade).

Todo o pensamento bakhtiniano tem como eixo norteador a interação verbal e seu caráter dialógico. Para o autor, aquele que enuncia, seleciona palavras apropriadas para formular uma mensagem que possa ser compreendida pelos destinatários. Por sua vez, o interlocutor interpreta e responde, de forma ativa, aquele enunciado, internamente (por meio de seus pensamentos) ou externamente (por meio de um novo enunciado oral ou escrito).

Essa compreensão responsiva implica posicionar-se, fornecer uma resposta à resposta situada no contexto do movimento interlocutivo, defende Bakhtin (2011, p. 271). 


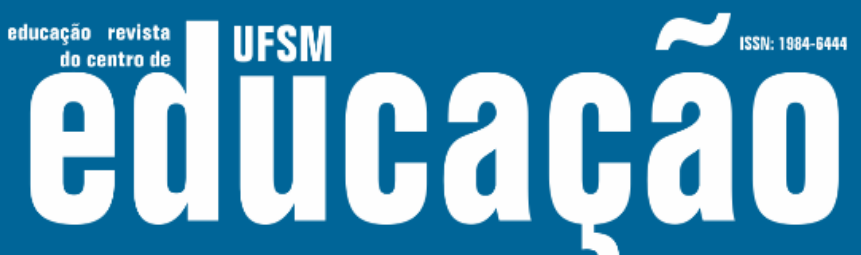

ISSN: 1984-6444 | http://dx.doi.org/10.5902/1984644432935

Toda compreensão da fala viva, do enunciado vivo, é de natureza ativamente responsiva. (...) toda compreensão é prenhe de respostas (...) o ouvinte se torna falante, sendo importante que a pesquisa não realize nenhum tipo de fusão dos dois pontos de vista, mas que mantenha o caráter dialógico, revelando sempre as diferenças e a tensão.

Se até, então, a referência à alteridade estava centrada no próprio Roberto, numa relação de mão única, gradativamente, seu comportamento vai oscilando de uma total falta de alteridade para uma alteridade extrema, graças à intervenção de Mari (uma velha conhecida, por quem Roberto nutria algum sentimento, ainda que reprimido), que serve de mediadora entre as duas culturas, facilitando a comunicação e a interação do chinês com Roberto, ao trazer um intérprete (entregador de pizza que conhecia o idioma de Jun) para conversar o argentino.

A partir desse dia, intensifica-se o desejo de Roberto de conhecer a língua e os acontecimentos da vida do chinês, operando um deslocamento significativo em seu comportamento; uma grande transformação na sua forma de ver e sentir o mundo. Como um estrangeiro em seu próprio universo social, e fantasiando as histórias que lia no jornal, Roberto sonha platonicamente com o amor de Mari.

Certa manhã, Roberto é despertado com o telefonema de um suposto tio de Jun, que vive na Província de Mendoza, que pede para chamá-lo. Ainda que não entenda uma só palavra, pelo tom emocionado do chinês, compreende que ele havia finalmente encontrado quem tanto procurava.

A possibilidade de Jun ir embora para uma preparando para uma terra diferente da sua, reavalia seu cotidiano, faz com que Roberto se conscientize de que é preciso se adaptar ao novo, aceitar as diferentes culturas, exercitar o diálogo e a alteridade, não havendo razão para temer uma vida junto à Mari, pois medo, intimidade e cumplicidade são elementos inerentes às relações amorosas.

Isso nos faz pensar que, numa sociedade como a nossa, cuja pluralidade de culturas, religiões, visões de mundo, etnias e outras dimensões das identidades humanas infiltram-se, de forma exponencial, o multiculturalismo emerge como um conceito a ser trabalhado nas instituições de ensino, mediante a criação de atos de currículo, que questionem a 'superioridade' dos saberes, gerais e universais, sobre os saberes particulares e locais. 


\section{工 Wusm Eutinará

ISSN: 1984-6444 | http://dx.doi.org/10.5902/1984644432935

$\mathrm{Na}$ medida em que, como docentes-pesquisadores, vivenciamos o dialogismo do discurso científico, quer na interação com nossos pares, com os diferentes teóricos estudiosos dos temas de nosso interesse ou, ainda, em nossa prática pedagógica, torna-se relevante considerar o lugar singular que cada indivíduo ocupa, para que possamos reconhecer nosso lugar na interlocução com o outro.

Nessa perspectiva, entendemos ser possível construir laços coletivos que possibilitem transformar o outro e nos transformarmos nas interações e trocas cognitivas, compartilhando excedentes de visão e exercitando a alteridade; o que, em última análise, constitui um ato de compromisso - responsável e responsivo, como nos ensina Bakhtin (2011).

Assim, conhecimentos vão sendo tecidos, de forma dialógica e interativa, nos diferentes espaçostempos que habitamos, formando uma rede de significações e sentidos, que amplia os limites individuais, resultando novas formas de agir e pensar.

Cabe destacar, porém, que não é adequado afirmar que o dialogismo se dá entre interlocutores. O dialogismo é sempre entre discursos, dado que o interlocutor só existe nesse contexto. $\mathrm{O}$ embate, portanto, se dá entre os discursos do locutor e interlocutor. Sobre isso, Brait (2005, p. 94-5) escreve:

Por um lado, o dialogismo diz respeito ao permanente diálogo, nem sempre
simétrico e harmonioso, existente entre os diferentes discursos que configuram
uma comunidade, uma cultura, uma sociedade. É nesse sentido que podemos
interpretar o dialogismo como o elemento que instaura a constitutiva natureza
interdiscursiva da linguagem. Por outro lado, o dialogismo diz respeito às
relações que se estabelecem entre o eu e o outro nos processos discursivos
instaurados historicamente pelos sujeitos, que, por sua vez, se instauram e são
instaurados por esses discursos.

Com efeito, o dialogismo na concepção bakhtiniana carrega dois sentidos básicos: o de princípio constitutivo da linguagem; ou seja, o modo de funcionamento real da linguagem; e uma forma particular de composição do discurso (Brait, 2012). Como decorrência da pluralidade e da alteridade - elementos que circundam as trocas discursivas, a autora assevera que, de acordo com Bakhtin (op. cit.), todos os enunciados são habitados por diferentes vozes provenientes de diversos falantes e de variados contextos.

Na presunção de que o cinema que nos faz pensar como gesto criativo, capaz de provocar a reflexão e o questionamento, é o cinema que 'educa', como afirmam 


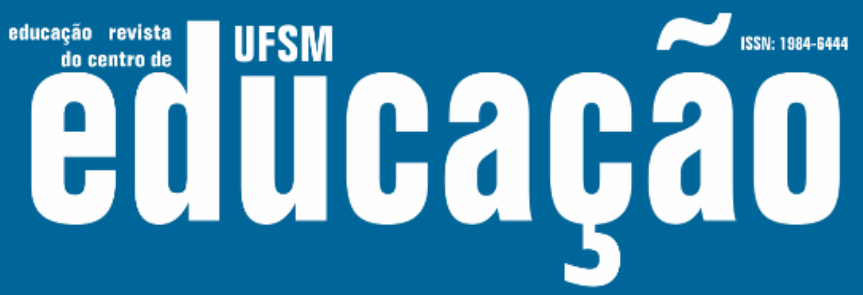

ISSN: 1984-6444 | http://dx.doi.org/10.5902/1984644432935

Xavier e Canen (2008) e, alinhados ao pensamento de Bergala (2008), trabalhamos, em nossa pesquisa, concebendo-o como espaço de criação e como hipótese de alteridade, no contexto universitário; ou seja, como um poderoso instrumento de comunicação, de sensibilização e de difusão de representações diversas da realidade; capaz de desestabilizar o instituído, provocando mudanças nas formas de aprenderensinar.

Desse modo, anteriormente à exibição do filme "Um conto Chinês", trouxemos informações sobre a temática, a equipe técnica, a filmagem, entre outras, que contribuíssem para melhor compreensão do tema, da trama, da linguagem e do lugar daquele filme no contexto da história do cinema, em nível nacional e mundial. Em seguida, propusemos aos praticantes que se organizassem em grupos para conversarem sobre a experiência vivenciada, considerando a forma como o filme os tocou, os pontos que gostariam de destacar, a importância das imagens para orientar ações práticas diárias, entre outros aspectos.

Como resultado, de um modo geral, os participantes gostaram do filme. Ressaltaram que, apesar de sua pegada mais próxima da comédia, o mesmo apresentava uma boa dose de humor negro, mas também os fazia pensar. Elogiaram o roteiro e a direção de Borensztein, por ter optado por uma linguagem comum, desprovida de formalismos, e colocar seu foco no personagem Roberto, trazendo para o cotidiano de sua vida, um pouco de exagero.

Praticante Laís S. - O roteiro é simples, com uma pitada de ironia. Há muito de comédia; mas há espaço para a reflexão e a emoção. A gente fica pensando sobre o motivo das coisas, se existe acaso, sobre o sentido da amizade (...).

Praticante Monique C. - Destaco o papel que o outro exerce em nossas vidas; a importância do diálogo e da interação entre os sujeitos, em suas constituições. Fiquei pensando sobre a necessidade de trabalharmos com nossos alunos questões como aceitação da diversidade, das diferenças, das desigualdades, entre outros aspectos.

Praticante Marco F. - Gostei muito da cena em que Roberto, cujo hobby é colecionar notícias incríveis e absurdas, descobre, perplexo, a verdadeira história de 


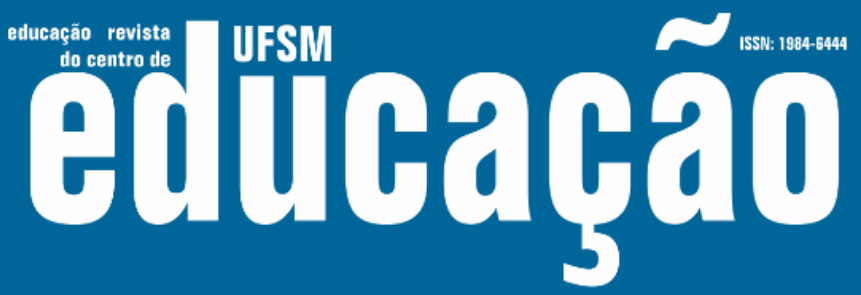

ISSN: 1984-6444 | http://dx.doi.org/10.5902/1984644432935

Jun, e exclama: "O que ele disse? Essa notícia era sobre ele? Essa era sua noiva? Não pode ser!".

O conteúdo mostrado permite-nos afirmar que a função do docente-mediador é a de propor desafios, criar atos de currículo com situações problematizadoras e intervir nas discussões, instigando os praticantes à busca da compreensão dos conceitos desenvolvidos, dando início à (re) construção de seus conhecimentos, de forma autoral, além de favorecer o surgimento de outras mediações.

Ao expressarem suas opiniões por escrito, os praticantes expuseram seus pensamentos, assinaram um compromisso com a verdade que produziram - um ato responsivo, como enfatizado por Bakhtin (2011), além de demarcarem um lugar de alteridade, possibilitando, dessa forma, o estabelecimento de uma relação dialógica, na qual a crítica, os confrontos ideológicos e o discurso polifônico se instituíram. Como vimos, mediante o uso de tecnologias digitais em rede foi possível engendrar atos de currículo, potencializando o processo de aprendizagem.

Tendo em vista aproximar saberes científicos e saberes comuns e, dessa forma, dar maior sustentabilidade ao trabalho proposto, sugerimos aos estudantes a leitura de dois artigos: Santos, E. e Okada (2003) e Santos, E. (2010).

Propusemos, então, que buscassem, no cinema, narrativas que apresentassem INVENÇÕES, atos de currículos sobre cotidianos educativos, dentro e fora do Brasil, tendo em mente que, para os cotidianos o que mais interessa são as operações de usuários, as práticas inovadoras. Organizamos as atividades da seguinte forma: (a) escolha do filme a resenhar; (b) apresentação de uma resenha crítica (duas páginas) que dialogasse com os conceitos e noções sobre currículos e cotidianos, já trabalhados, podendo ser acrescentadas outras discussões; e (c) escolha de um filmeresenha apresentado por um colega, que deveria ser comentado. ( $O$ colega que tivesse a resenha comentada deveria dialogar com o autor do comentário, para que todos participassem dos debates).

A resenha crítica do filme "Entre os Muros da Escola", apresentada, a seguir, pela praticante Thaís R., a exemplo de "Um Conto Chinês", aborda o tema do multiculturalismo, de grande atualidade e pertinência, fazendo-nos refletir sobre a problemática da diversidade cultural, as consequências advindas da interação dessas 


\section{Autuaŗão}

ISSN: 1984-6444 | http://dx.doi.org/10.5902/1984644432935

culturas, os desafios que se colocam aos professores, e as estratégias de que lançam mão em suas práticas educativas.

Praticante Thaís R. - Sinopse do Filme "Entre os muros da escola"

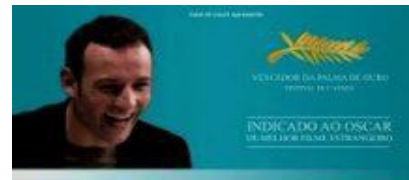

ENTRE OS MUROS DAESCOLA

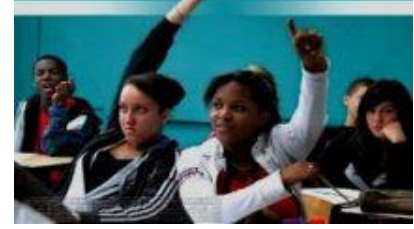

Ficha técnica:

Título: Original: Entre les Murs.

Origem: França, 2008.

Direção: Laurent Cantet.

Roteiro: Laurent Cantet, François Bégaudeau e Robin Campillo, baseado em livro de François Bégaudeau.

\section{Elenco:}

François Bégaudeau, Nassim Amrabt, Laura Baquela, Cherif Bounaïdja Rachedi, Juliette Demaille, Dalla Doucoure, Arthur Fogel e Damien Gomes.

François Marin trabalha como professor de língua francesa em uma escola, localizada na periferia de Paris. Ele e seus colegas de ensino buscam apoio mútuo na difícil tarefa de fazer com que os alunos aprendam algo ao longo do ano letivo. Marin tem na escola alunos problemáticos, violência, tensões étnicas entre os alunos, o que testa sua paciência e, mais importante, sua determinação como um educador.

\section{Resenha do filme "Entre os muros da escola"}

O filme "Entre os muros da escola" apresenta um contexto social caracterizado pelo choque cultural existente entre os indivíduos de uma escola localizada na periferia de Paris. A história se passa com alunos adolescentes na faixa etária dos 13 a 15 anos, oriundos de diferentes etnias, como asiáticos, chineses, latinos e afrodescendentes, todos predominantes das classes populares. Com tanta diferença cultural e social, os conflitos nas relações cotidianas tornam-se constantes.

Os problemas sociais vivenciados por esses alunos são refletidos diretamente na escola. Podemos destacar, por exemplo: a deportação da mãe de um aluno chinês, chamado Wei, e o caso do aluno Souleymane, definido pelos professores como "problemático", com um histórico de agressões verbais e físicas aos docentes e a outros alunos. Por conta disso, o referido aluno é citado no conselho de classe para que seja alcançada uma medida punitiva para seu comportamento inadequado. No entanto, os educadores deparam-se com um obstáculo social: a expulsão do aluno resultará no seu retorno ao país de origem.

Essas divergências culturais, em dados momentos acarretam dificuldades de comunicação entre escola e família. Fato ocorrido com o já citado Souleymane, que tem como 


\section{Autuaŗão}

ISSN: 1984-6444 | http://dx.doi.org/10.5902/1984644432935

seu responsável sua mãe, que somente se comunica através de seu dialeto de origem. Nesse contexto fica muito difícil manter a qualidade do ensino.

Portanto, podemos notar que o contexto social está intimamente ligado ao cotidiano escolar, interferindo no processo de ensino-aprendizagem das escolas. Por conta disso, devese não menosprezar, e sim, fazer uso do contexto social de modo que colabore positivamente com a dinâmica escolar.

Em relação ao contexto escolar, trata-se de uma escola pública e tradicional da periferia de Paris, a qual volta-se para alunos filhos de imigrantes, majoritariamente pobres, e visa educar para sua incorporação à cultura francesa. Além dos conteúdos curriculares básicos, a escola tenta passar àqueles diferentes sujeitos o "modo correto de falar e se comportar naquele país". É como se fosse um processo civilizatório, o qual ignora a cultura de cada indivíduo e introduz naqueles imigrantes a cultura local.

Em meio a essa situação, encontramos defasadas metodologias pedagógicas, com aulas expositivas e sem muitos recursos. Os professores durante os conselhos de classe não chegam a um consenso quanto às metodologias de ensino-aprendizagem, de valorização do estudante ou de práticas de advertências. Impacientes, perdidos diante das atitudes dos alunos, não sabem como conciliar as punições e o contexto social dos alunos que, estressados, agem com desrespeito, apresentando baixo rendimento, falta de atenção e pouca participação durante as aulas, sempre questionando a autoridade do professor. Por conta disso, a rotina caracteriza-se pela falta de interesse, desrespeito, insultos, violências de ambas as partes (educadores e alunos); enfim, conflitos oriundos de diversas razões.

MORAIS, R. (org.). Sala de aula: que espaço é este? 14a ed.. São Paulo: Papirus, 2001, p. 17-29 Como constatamos, a universidade como espaço legítimo no qual se dá o processo de socialização, e onde, inexoravelmente, o convívio multicultural se impõe, constitui o ambiente propício à discussão acerca da diversidade - cultural, racial, social, entre outras. Isso implica capacidade de se colocar no lugar do outro, em uma relação baseada no diálogo e na valorização das diferenças existentes.

Disponivel em: http://docenciaonline.pro.br/moodle/. Acesso em 01.06.2018.

No limiar entre o uso 'escolarizado', que restringe o cinema a um recurso didático, e o uso do cinema como objeto da experiência estética e expressão da sensibilidade, do conhecimento e das múltiplas linguagens humanas é que se encontra o material para criação de outras possíveis práticas escolares, permitindo que o processo aprendizagemensino reencontre a cultura ao mesmo tempo cotidiana 


\section{Autuarão}

ISSN: 1984-6444 | http://dx.doi.org/10.5902/1984644432935

e elevada, pois o cinema é o campo no qual a estética, o lazer, a ideologia e os valores sociais mais amplos são sintetizados numa mesma arte. Olhar as imagens de dentro, de modo a ir além da posição daquele que a coisifica, delas se apropria e as interpreta (FISCHER, 2008), é deixar-se tocar pela experiência do autor, do diretor, da personagem e do espectador. Ao propormos desafios, criarmos situações problematizadoras e intervirmos nas discussões, instigamos os praticantes à busca da compreensão dos conceitos desenvolvidos, dando início à (re)construção de seus conhecimentos, de forma autoral, além de favorecermos o surgimento de outras mediações.

Como podemos constatar, a seguir, a resenha de Thaís suscita outros tantos comentários de seu grupo.

Praticante Thaís B.: Esse filme é muuito legal! Boa escolha, Thaís!

Docente-pesquisadora: Esse filme é muito interessante e, como você mesmo aponta, temos situações semelhantes no nosso país. Diferenças sociais, culturais e étnicas, pensamentos e valores diferenciados estão presentes em nossos cotidianos escolares, e constituem um desafio permanente para educadores, que devem refletir sobre suas práticas pedagógicas, a fim de minimizar/ evitar os conflitos emergentes.

Em relação ao texto desenvolvido, penso que sua apresentação poderia ter sido feita, de forma linear, encadeada, sem necessidade de dividi-lo em tópicos, destacando os principais argumentos utilizados pelo autor, para tecer sua mensagem. Também senti falta do alinhamento da narrativa às questões levantadas nos diferentes textos, entrevistas e comentários sobre currículos, imagens e cotidianos, aqui disponibilizados. Traga algumas contribuições daqueles autores para sua resenha.

Aspectos comportamentais por parte dos alunos e professores que não sabem lidar com esses conflitos, associada à precariedade metodológica, são tônicas do filme, e você já nos disse como exploraria essas questões: Trabalharia com ele para falar sobre assuntos de regras, respeito, diferença, diversidade. Usaria uma perspectiva de reflexão e de conscientização.

No entanto, não podemos esquecer que, ao lado dos saberes cotidianos, transitam os saberes científicos; ou seja, o dentrofora da escola contempla, além de 


\section{تuthapẫ}

ISSN: 1984-6444 | http://dx.doi.org/10.5902/1984644432935

questões relacionadas a atitudes e valores, o desenvolvimento de conhecimentos e habilidades básicos, presentes no currículo oficial. Em face disso, indago:

- Que aspectos do currículo formal você poderia explorar a partir da diversidade observada no filme, nas diferentes áreas do conhecimento? Para qual público?

- Que outros recursos você poderia associar ao filme, tendo em vista ampliar esses conhecimentos, de forma colaborativa e, se possível, autoral?

- Qual seria o seu papel como docente, nesse contexto?

Pense sobre isso, e voltemos a conversar!

Praticante Thaís R.: O filme retrata um cotidiano escolar muito complicado, permeado de brigas, conflitos, diversidade, intolerância e desrespeito. Esse cotidiano não nos é estranho, dado que diferenças sociais, culturais e étnicas, pensamentos e valores diferenciados estão presentes em nossas escolas, e constituem um desafio permanente para educadores, que devem refletir sobre suas práticas pedagógicas, a fim de minimizar ou evitar os conflitos emergentes. O que não pode ocorrer é o professor utilizar de sua autoridade para minimizar e discriminar seus alunos. Por isso, acho que devemos ficar atentos não só às questões das relações sociais, mas também aos aspectos que envolvem o processo ensino aprendizagem. Isso me faz pensar e questionar sobre qual currículo perpassa esse cenário? que intencionalidade e relações de poder são intrínsecas a ele? será que o currículo oficial consegue ser posto em prática nesse contexto? será que o currículo oficial está condizente com o currículo oculto?

Penso, que a partir de um currículo formal, principalmente nas disciplinas de história, literatura, artes e até ensino religioso, seja possível trabalhar questões como diversidade cultural, respeito e tolerância. Os próprios conteúdos inerentes a essas áreas podem ser ampliados, buscando-se uma perspectiva mais crítica e reflexiva. (...) Temas como indígenas (ex.: catequização) e afrodescendentes (ex.: escravidão) podem ser explorados para além do fato histórico, onde identificamos o grupo dominante e o dominado. Não só transmiti-los, ou apresentá-los "de forma superficial", mas sim trabalhar os conteúdos, comparando-os, trazendo outros elementos e identificando as relações sociais existentes neles. 


\section{Dism etuluará}

ISSN: 1984-6444 | http://dx.doi.org/10.5902/1984644432935

Para mim, essa prática não deve ser direcionada a um público específico, restrito e limitado; pelo ao contrário, deve estar presente em todas as séries, desde os anos iniciais do ensino fundamental; claro, respeitando as características dos discentes e estando de acordo com o grau de complexidade dos conteúdos. Além disso, indico um texto1 que apresenta uma discussão interessante sobre autoridade e autoritarismo, pois acredito que esses aspectos estão presentes no nosso cotidiano escolar e interferem diretamente nas nossas relações pedagógicas.

Docente-pesquisadora: Excelente reflexão sobre as questões por mim levantadas. Destaco uma questão, apontada por você, de grande relevância para o processo educativo: a busca de uma perspectiva mais crítica e reflexiva na abordagem dos conteúdos, preocupação que deve estar presente, como um fundamento educativo, em todos os níveis de ensino.

Para tanto, torna-se necessário que o professor promova situações de aprendizagem que estimulem o diálogo e o sentido de compartilhamento entre todos os participantes desse processo, que aprendem e ensinam, de forma interativa. Nessa perspectiva, a aprendizagem se realiza, pelo esforço de reconstrução empreendido pelo aluno, mediado pelo professor.

É sempre bom enfatizar que o discurso do professor, a Internet, ou um curso, só tem o poder de transmitir informações, pois nossa mente não é uma caixa vazia, uma folha em branco a ser preenchida. Transformar informação em conhecimento dependerá do esforço, da disciplina e do empenho de cada indivíduo, ou tudo não passará de um amontoado de palavras ou dados inúteis, uma perda de tempo, um desperdício em todos os sentidos.

\section{Parabéns!9}

Praticante Thaís R.: Que bom que você gostou, confesso que fiquei meio perdida na hora de fazer a resenha, vem diversas questões na cabeça, mas na hora de escrever tudo se perde RSRSRS. Com a sua intervenção fica tudo mais claro e fácil. Obrigada!

Beijos, Thaís. 9 


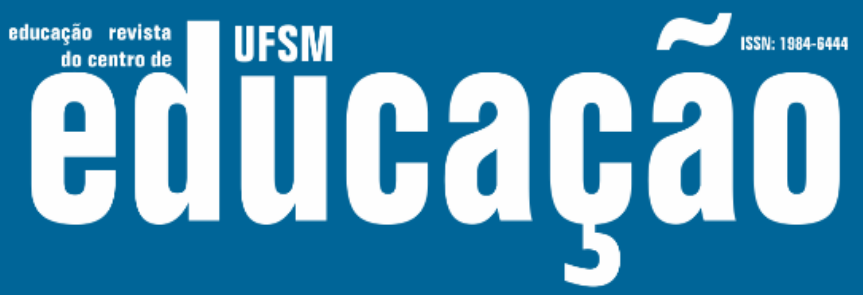

ISSN: 1984-6444 | http://dx.doi.org/10.5902/1984644432935

O conteúdo mostrado permite-nos afirmar que a função do mediador é a de propor desafios, criar situações problematizadoras e intervir nas discussões, instigando os praticantes à busca da compreensão dos conceitos desenvolvidos, dando início à (re)construção de seus conhecimentos, de forma autoral, além de favorecer o surgimento de outras mediações. Ao expressarem suas opiniões por escrito, os praticantes expuseram seus pensamentos, assinaram um compromisso com a verdade que produziram - um ato responsivo, como enfatizado por Bakhtin (2011), além de demarcarem um lugar de alteridade, possibilitando, dessa forma, o estabelecimento de uma relação dialógica, na qual a crítica, os confrontos ideológicos e o discurso polifônico se instituíram. Como vimos, mediante o uso de tecnologias digitais em rede foi possível engendrar atos de currículo, potencializando o processo de aprendizagem.

\section{Conclusão}

Assim como a linguagem escrita nos permite tomar consciência realidade e de nossa cultura, sistemática e conceitualmente, imagens estáticas, ou em movimento, constituem as narrativas do mundo contemporâneo, fornecendo-nos novos elementos para compreendermos o próprio conceito de narrativa.

A partir dessa ótica, as práticas pedagógicas podem ser analisadas por meio de suas representações imagéticas ou descrições verbais ou, ainda, na articulação entre essas linguagens. É nesse contexto que o cinema pode ser utilizado para potencializar currículos multirreferenciais, baseados em processos de aprendizadoensino que impliquem o desenvolvimento da reflexão e da capacidade crítica e criadora, a partir da articulação e vivência dos saberes numa perspectiva de pluralidade; o que demanda priorizar as relações, a heterogeneidade, o diálogo, a alteridade, entre outros.

Neste artigo, apresentamos como pano de fundo, o filme "Um Conto Chinês", para discutirmos questões relacionadas à multiculturalidade, aos processos dialógicos e à alteridade, tão presentes em nossos cotidianos, como pudemos vivenciar, no 


\section{Autนaดูลิ}

ISSN: 1984-6444 | http://dx.doi.org/10.5902/1984644432935

âmbito da pesquisa que realizamos na Graduação em Educação da UERJ, ao longo do curso de Doutorado.

Como experiência única de um ser em aprendizagem, a formação emergiu a partir de modelos propositivos e explicativos engendrados por meio de atos de currículo que estimularam a ajuda mútua, a tecitura do conhecimento, de forma coletiva, a participação em debates e o desenvolvimento da autonomia e de autorias diversas.

Ao abordarmos essas questões, a partir de narrativas cinematográficas, era nosso propósito articular mídia e educação, buscando o diálogo entre saberes científicos e os do cotidiano, na tentativa de dialogar com o poder instituído, que insiste em modelar e, muitas vezes engessar, iniciativas docentes que visam potencializar nossa leitura do mundo. Nesse sentido, ampliamos nosso olhar e inovamos nosso modo de fazer, sentir e agir, além de ativar nosso poder criador num processo de aprendizagem significativa, em cotidianos reinventados.

\section{Referências}

ALVES, Nilda. Decifrando o pergaminho: os cotidianos das escolas nas lógicas das redes cotidianas. In: Oliveira, Inês. B.; Alves, Nilda (Orgs.). Pesquisa nos/dos/com os cotidianos das escolas. Petrópolis: DP et Alii, 2008, p. 15-38. ISBN: 978-8560985-32-6.

AMARAL, Mirian M. Autorias docente e discente: pilares de sustentabilidade na produção textual e imagética em redes educativas presenciais e online. Tese de doutora. UNESA, 2014.

BAKHTIN, Mikail. Estética da criação verbal. São Paulo: Martins Fontes, 2011. ISBN: 978-85-7827-470-2.

BAUMAN, Zygmunt. Modernidade líquida. Trad. Plínio Dentzien. Rio de Janeiro: Zahar, 2001. ISBN: 13: 978-8571105980.

BENJAMIM, Walter. Magia e técnica, arte e política: obras escolhidas. São Paulo: Brasiliense, 1996, v.1. ISBN: 978-85-1115-628-7.

BERGALA, Alain. A hipótese-cinema: pequeno tratado de transmissão do cinema dentro e fora da escola. Rio de Janeiro: Booklink e CINEAD/UFRJ, 2008. ISSN: 1809-5747. 


\section{A Husm Eutlagha}

ISSN: 1984-6444 | http://dx.doi.org/10.5902/1984644432935

BRAIT, Beth. Bakhtin e a natureza constitutivamente dialógica da linguagem. In: Brait, Beth (Org.). Bakhtin - dialogismo e construção do sentido. $2^{\underline{a}}$ ed. Campinas: Unicamp, 2005. ISBN: 8526806823.

CANEN, Ana; XAVIER, Giseli Pereli de M. Multiculturalismo, pesquisa e formação de professores: o caso das diretrizes curriculares para formação docente. Ensaio: avaliação e políticas públicas em educação. Rio de Janeiro: Fundação Cesgranrio, jul./set. 2005, v.113, no 48, p.333-44.

CERTEAU, Michael de. A invenção do cotidiano: artes de fazer. Petrópolis: Vozes, 1996. ISBN: 978-85-326-1148-2.

COSTA, Elzimar G. M. Espanhol: língua de encontros. In: Sedycias, J. (Org.). 0 ensino do espanhol no Brasil: passado, presente, futuro. São Paulo: Parábola, 2005, p. 6170. ISBN: 9788588456327.

DELEUZE, Gilles. A imagem-tempo. São Paulo: Brasiliense, 2007 (Cinema 2). ISBN: 10: 8511220283.

DIDI-HUBERMAN. Georges. Sobrevivência dos vaga-lumes. Trad. Vera Casa Nova e Márcia Arbex. Belo Horizonte, MG: UFMG, 2011. ISBN: 8570418892.

DUARTE, Rosalia; ALEGRIA, João. Formação estética audiovisual: um outro olhar para o cinema a partir da educação. 2008. Disponível em: http://seer.ufrgs.br/educacaoerealidade/article/viewFile/6687/4000. Acesso em 02 out. 2018.

FANTIN, Mônica. Mídia-educação e cinema na escola. Teias. Rio de Janeiro, jan./dez. 2007, ARTIGOS, ano 8, no 15-16, p. 1-13. 1518-5370 [impresso] • 1982-0305 [eletrônico].

FISCHER, Rosa M. B. Imagens da mídia, educação e experiência. In: Girardello, Gilka; Fantin, Mônica. Liga, roda, clica: estudos em mídia, cultura e infância. Campinas; Papirus; 2008. ISBN: 9788530808693.

FREIRE, Paulo. Pedagogia da autonomia. Rio de Janeiro: Paz e Terra, 2004. ISBN: 10: 8577530159 .

FRESQUET, Adriana. Cinema e educação: reflexões e experiências com professores e estudantes de educação básica, dentro e "fora" da escola. Belo Horizonte: Autêntica (Coleção Alteridade e Criação), 2013. ISBN: 9788582172605/ ISSN: 8582172605.

GALLO, Sílvio. Eu, o outro e tantos outros: educação, alteridade e filosofia da diferença. II CONGRESSO INTERNACIONAL COTIDIANO: DIÁLOGOS SOBRE DIÁLOGOS. Universidade Federal Fluminense, Rio de Janeiro, 2008. 


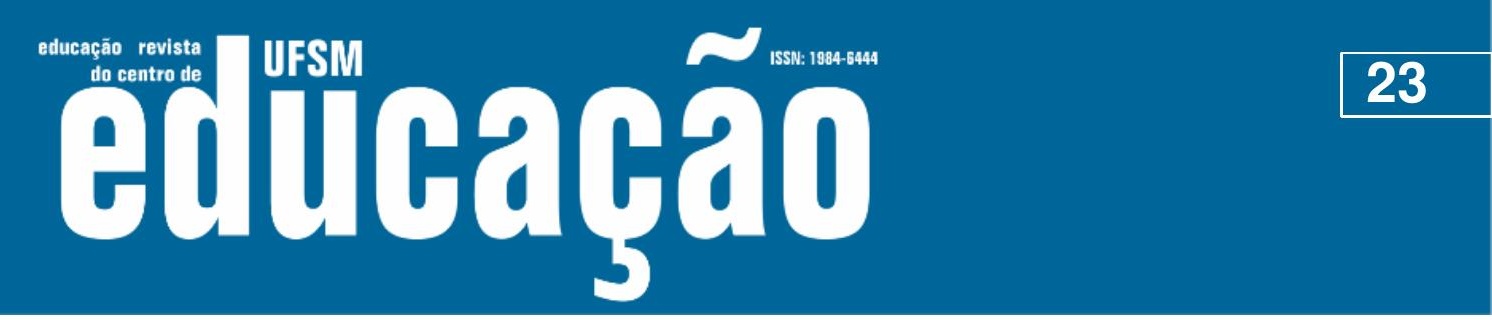

ISSN: 1984-6444 | http://dx.doi.org/10.5902/1984644432935

MACEDO, Roberto S.. Multirreferencialidade: o pensar de Jacques Ardoino em perspectiva e a problemática da formação. In: Macedo, Roberto S. C.; Barbosa, Joaquim G.; Borba, Sérgio. (Orgs). Jacques Ardoino \& a educação. Belo Horizonte: Autêntica (Coleção Pensadores @ Educação), 2012. Disponível em: https://formacce.ufba.br/jacques-ardoino-educacao. Acesso em: 14 mai.2018.

McLUHAN, Marshall. Os meios de comunicação como extensão do homem. São Paulo: Cultrix, 1964. Revista de Administração de Empresas. São Paulo jul.-set. 1969. ISSN: $0034-7590$ (impresso) ISSN: 2178-938X (online). Disponível em: http://www.scielo.br/scielo.php?script=sci_arttext\&pid=S003475901969000300009. Disponível em: 14 dez. 2018.

PAULA, Luciane. O dizer estético e antiético da mídia - a veridictoriedade à luz da perspectiva bakhtiniana. In: Osório, Ester M. R. (Org.). Bakhtin na prática. 2008. Revista de Literatura e Linguistica - Eutomia. ISSN: 1982-6850. Disponível em: https://periodicos.ufpe.br/revistas/EUTOMIA/article/view/1798. Acesso em: 13 dez. 2018.

SANTOS, Boaventura. Uma outra universidade possível: processos desiguais e combinados para descolonizar a universidade no mundo. Conferência. IX SEMINÁRIO INTERNACIONAL. AS REDES EDUCATIVAS E AS TECNOLOGIAS: EDUCAÇÃO E DEMOCRACIA - APRENDERENSINAR PARA UM MUNDO PLURAL E IGUALITÁRIO. 2017.

SANTOS, Edmea. As imagens e a educação online: convergências entre o cinema e os fóruns de discussão no contexto de uma pesquisa-formação multirreferencial. In: BERINO, Aristóteles; SOARES, Conceição. (Orgs.).

Educação e imagens: instituições escolares, mídias e contemporaneidade. Rio de Janeiro: DP et Alii, 2010, v. 1, p. 105-24. ISBN: 9788561593353

SANTOS, Edmea; OKADA, Alexandra. A imagem no currículo: da crítica à mídia de massa a ações de autorias dialógicas na prática pedagógica. Revista da FAEEBA Educação e Contemporaneidade. Salvador, jul./dez. 2003, v. 12, n. 20, p. 287-97. ISSN: 2358-0194.

SOUZA, Fábio M. O cinema como mediador na (re)construção de crenças de professores de espanhol - língua estrangeira em formação inicial. Tese Doutorado em Educação. São Paulo: Faculdade de Educação da Universidade de São Paulo, USP, 2014. Disponível em: www.teses.usp.br/teses/disponiveis/48/.../FABIO_MARQUES_DE_SOUZA_rev.pdf. Acesso em: 14.dez.2018.

XAVIER, Gisele Pereli de M.; CANEN, Ana. Multiculturalismo e educação inclusiva: contribuições da universidade para a formação continuada de professores de escolas públicas no Rio de Janeiro. Pro-posições, set./dez.2008, v, 19, № 3 (57), p. 225-42. ISSN: 0103-7307 e 1980-6248. 


\section{T uss 2

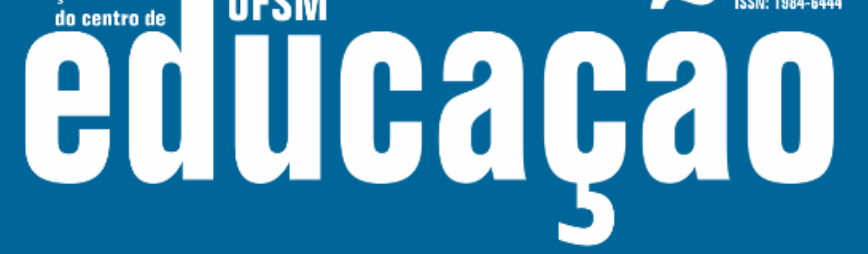

ISSN: 1984-6444 | http://dx.doi.org/10.5902/1984644432935

\section{Correspondência}

Mirian Maia do Amaral - Professora doutora da Fundação Getúlio Vargas (FGV), Rio de Janeiro, Rio de Janeiro, Brasil.

Rosemary dos Santos - Professora doutora da Universidade do Estado do Rio de Janeiro (UERJ), Rio de Janeiro, Rio de Janeiro, Brasil.

Edméa Oliveira dos Santos - Professora doutora da Universidade do Estado do Rio de Janeiro (UERJ), Rio de Janeiro, Rio de Janeiro, Brasil.

Fundação Getúlio Vargas (FGV). Praia de Botafogo, 190 - Botafogo, CEP: 22250900. Rio de Janeiro, Rio de Janeiro, Brasil.

E-mail: amaral3378@gmail.com - brisaerc@hotmail.com-edmeabaiana@gmail.com

iD ORCID: http://orcid.org/0000-0002-0647-6427 - http://orcid.org/0000-0003-04791703 - http://orcid.org/0000-0003-4978-9818

\section{(C) $(1) \Theta$}

This work is licensed under a Creative Commons Attribution-NonCommercial 4.0 International (CC BY-NC 4.0) 